American Journal of Applied Sciences 8 (12): 1384-1387, 2011

ISSN 1546-9239

(C) 2011 Science Publications

\title{
Role of Information Technology Infrastructure Library in Data Warehouses
}

\author{
Tariq Rahim Soomro and Hasan Yousef Wahba \\ Faculty of Engineering and Information Technology, \\ Al Ain University of Science and Technology, Al Ain, UAE
}

\begin{abstract}
Problem statement: The Information Technology Infrastructure Library (ITIL) is most widely used de-facto- standard, consists of set of concepts and practices for Information Technology Service Management (ITSM), IT development and IT operations. Approach: Where as a Data Warehouse (DW) is a relational database used for the purpose of query and analysis to generate complex reports for enterprises. Results: This study introduces ITIL and DW, along with DW concepts and challenges and will review how to map ITIL with DW. Conclusion: This study identified that ITIL will play vital role when and where used in Data warehouses, specifically in the form of availablilty management; IT service continuity management; capacity management; financial management; and service level management.
\end{abstract}

Key words: Information Technology Infrastructure Library (ITIL), data warehouse, service delivery, IT development, Information Technology Service Management (ITSM), Online Analytical Processing (OLAP), DW concepts, Office of Government Commerce (OGC), service management

\section{INTRODUCTION}

The Information Technology Infrastructure Library (ITIL) is a framework developed by the UK's Office of Government Commerce (OGC). It is best practice in Information and Communication Technology (ICT) Service Management ITIL.org-Overview, ITIL.org. ITIL is the worldwide de-facto-standard for service management and contains broad and publicly available professional documentation on how to plan, deliver and support IT service features (Potgieter et al., 2004). On the other hand a data warehouse is an integrated and time-varying collection of data primarily used in strategic decision making by means of Online Analytical Processing (OLAP) techniques (Husemann et al., 2000). The coordination of specific, technical and organizational resources to provide added value to the customer through services are the objective of service management. According to ITIL, service management is a framework and it contains all the necessary and specialized organizational capabilities available for the generation of added value to the customer as services, which include service strategies, service design, service transitions, service operations and continual service improvements ITIL.org-Service Management, ITIL.org. As we are aware that, every business requires complete, accurate and timely information to grow the business and to run various operations of the business. This is not an easy job to achieve where there is lot of data around us. Achieving this objective and level of information requires transforming, reconciling; maintaining information and delivering it in real time to the people, processes and applications that need it. On the other hand access to timely, accurate information is critical as enterprises look forward to drive rapid growth through innovation IBM Information Sphere, IBM.

Data Warehouse market is continuing to experience incredible growth, primarily because of the role of data warehouse as a powerful decision support tool (Sen et al., 2011). A data warehouse is in place for following key markets (Ponniah, 2001):

\section{Retail:}

- Customer loyalty

- Market planning

Financial:

- Risk management

- Fraud detection

Corresponding Author: Tariq Rahim Soomro, College of Engineering and Information Technology, Al Ain University of Science and Technology, Al Ain, UAE 
Am. J. Applied Sci., 8 (12): 1384-1387, 2011

Airlines:

- Route profitability

- Yield management

\section{Manufacturing:}

- Cost reduction

- Logistics management

\section{Utilities:}

- Asset management

- Resource management

\section{Government:}

- Manpower planning

- Cost control

Today Business Intelligence and Data Warehouse solutions are in place to entertain information requirement of the organization and to empower the IT teams to quickly and agilely respond to business users' information queries. This study is focusing on the solution, which is provided by OGC; That promise to improve customer Satisfaction and Service Quality of an enterprise (Potgieter et al., 2004). This study is organized as follows: next section will discuss DW concepts and challenges. Latter section will explore how to map ITIL with DW and finally conclusion of this mapping will be reviewed.

Data warehouse concepts and challenges: In order to introduce any best practice and solution to implement a data warehouse, it is necessary to under key components and issues with data warehouse. Following are the key components of a Data Warehouse:

- Source data component

- Data staging component

- Data storing component

- Information delivery component

- Metadata component

- Management and control component

Following are the common questions before building a Data Warehouse:

- Develop criteria for assessing the value

- Decide on the type to be built

- Where to keep it
- Where the data is going to come from

- Whether you have all needed data

- Who will be using the data warehouse

- How they will use it

- What times they will use it

Implementing a data warehouse is really a challenge. Data Warehouse projects tend to be costly. Despite the fact that the projects require large investments, both in terms of money and effort, despite this booming market, a large number of Data Warehouse initiatives end up as failures. It is therefore critical for the Data Warehouse community to devote more thought to understanding what afflicts Data Warehouse design, development, implementation and management. Data Warehouse initiatives often end up as failures because of factors such as slipped schedules, unacceptable performance, expandability problems, poor availability, complicated tools, poor data quality and unhappy users (Sen et al., 2011).

A Data Warehouse Processes (DWP) can be divided into two types of process which are Development Process and Management Process. Development Processes can include business requirements analysis, data design, architecture design, data mapping, ETL (Extraction, Transformation and Load) design, end user application design, end-user cube design, implementation and deployment (Sen et al., 2011). Operations tasks are generally responsible for making sure that the data warehouse keeps functioning as designed. Operations tasks in a DWP include metadata management, recovery management, financial services management, data warehouse governance, data governance and service level management. Other operations tasks in a DWP provide customer service/support consistently in a timely manner to the end users by supplying high quality and valuable data. These tasks include supporting business users, training business users, managing the technical infrastructure, information delivery management, tuning for database performance and service level agreement. This highlights the need to use some best practises to implement a Data Warehouse system. From best practices standpoint, both Capability Maturity Model Integration (CMMI) and ITIL could be applied to a data warehouse organization for process improvement (Sen et al., 2011; Darmawan et al., 2009). However, CMMI is better suited for application development and development of a data warehouse system and ITIL is better suited for improving data warehouse operations on Service Delivery and Service Support (Darmawan et al., 2009). 
How to map ITIL with DW: Currently ITIL is no doubt de-facto-standard but implementation of ITIL in various enterprises (ITIL, 2011) proves that it is the hope for all. Following are the possibilities of use of ITIL in Data Warehouses.

Availability management: Availability Management refers to ensure the delivery of IT services where, when and to whom they are required, by planning and building reliable and maintainable infrastructure and maintaining key support and supply relationships according to service requirements (Brooks, 2006). In Data Warehouse same process can be used for ensuring all functions of a data warehouse is available to the customer when they are needed and so on. The process depends on critical success factors such as reliability, maintainability, high availability (redundancy) and serviceability of the data warehouse (Darmawan et al., 2009).

Information technology services vontinuity management: The goal of IT Service continuity Management is to support the overall Business continuity Management process, by ensuring that the required IT technical and services facilities (including computer systems, networks, applications, telecommunications, technical support and service desk) can be recovered with required and agreed, business timescale (Brooks, 2006). In Data Warehouse same concept can be used when the data warehouse is 'down' or its information is not available. Also cost to the customers should determine necessary plans and countermeasures (Darmawan et al., 2009).

Capacity management: Capacity Management refers to ensure the best use of appropriate IT infrastructure to meet business needs currently and in the future through a proper understanding of both business and infrastructure requirements (Brooks, 2006). When mapping to Data Warehouse this helps to determine a matrix of 'optimum' resources needed to support the business. And to determine customer requirements and its impact on demand management, workload management and performance management for a data warehouse organizations (Darmawan et al., 2009).

Financial management: Accounting for the costs of providing IT service and recovering these costs from clients in an reasonable manner (IT Operation to Global Standards, 2011). In terms of data warehouse it can be used for tabulating the costs for customer service and to determine the value of a cost per unit of service; e.g., what is the cost of developing a report? or what is the cost of running the report? (Darmawan et al., 2009).

Service level management: To maintain and improve IT service quality through a constant cycle of identifying, agreeing to, monitoring and reporting on IT Service achievements. This process involves more than just creating Service Level Agreements (SLA) (Sharma and Rishi, 2011). While mapping to Data Warehouse this deals with SLA, service catalogue, service requirement, IT capability. This improves reporting specifications and service requirement of the Data Warehouse and finally it helps to balance business demands and the organization service ability (Darmawan et al., 2009).

\section{MATERIALS AND METHODS}

Following (Table 1) shows that possible processes of ITIL can help Data Warehouse.

\section{RESULTS AND DISCUSSION}

Today's business environment is totally depends on Information Technology (IT) and IT environment is becoming more and more complex then it was previously, because of rapid rate of change and cost. IT experts need a way to better map IT services with business objectives, to make the long-term cost of IT services lower and to imporve the quality of IT Services and ITIL is an right choice for data warehouses to help with these issues (Darmawan et al., 2009).

Table 1: Processes of ITIL

\begin{tabular}{ll}
\hline ITIL processes & Role of ITIL in data warehouse \\
\hline Availability management & $\begin{array}{l}\text { ITIL is ensuring all fucntions of } \\
\text { data warehouse is available to the } \\
\text { customer, when and where } \\
\text { they are reuqired. }\end{array}$ \\
ITIL support data warehouse \\
when the data warehouse is 'down' \\
or its information is not availbale \\
for any reason. \\
ITIL helps to determine a matrix \\
of optimum resources required to \\
support business in the form of \\
demand management, \\
workload management and \\
performance management. \\
ITIL determine the value of cost \\
per unit of service and helps \\
tabulating the costs for customer \\
services. \\
ITIL deals with Service Level \\
Agreement, Service catalogue, \\
Finacnial management & $\begin{array}{l}\text { Service requirement and helps to } \\
\text { balance business needs and } \\
\text { the organization serviceability. }\end{array}$ \\
\hline Service level management &
\end{tabular}




\section{CONCLUSION}

According to OGC, ITIL will improve Customer Satisfaction and Service Quality; and in this study we tried to establish that the use of ITIL in Data Warehouses in the form of Availability Management, IT Service continuity Management, capacity Management, Financial Management and Service Level Management is possible and useful. The role of ITIL is very promising and those enterprises that are using Data Warehouses should get full advantages of using it from DW point of view.

\section{REFERENCES}

Brooks, P., 2006. Metrics for IT Service Management. 1st Edn., Van Haren Publishing, Zaltbommel, ISBN-13: 9789077212691, pp: 202.

Darmawan, B., G. Chen and L. Varkonyi, 2009. Endto-End Availability and Performance Management using IBM Tivoli Solutions.

Husemann, B., J. Lectenborger and G. Vossen, 2000. Conceptual data warehouse design. Proceedings of the International Workshop on Design and Management of Data Warehouses, Jun. 5-6, Stockholm, Sweden, pp: 1-11.
IT Operation to Global Standards, 2011. IT Operation to Global Standard Satit Prasitwuttivech Consultant Datacraft (Thailand) Ltd.

ITIL, 2011. Why Implement ITIL in Your Organisation? ILX Group. http://www.itiltraining.com/itil-benefits.asp

Ponniah, P., 2001. Data Warehousing Fundamentals: A Comprehensive Guide for IT Professionals. 1st Edn., John Wiley and Sons, New York, ISBN-13: 9780471412540, pp: 516.

Potgieter, B.C., J.H. Botha and C. Lew, 2004. Evidence that use of the ITIL framework is effective. Proceedings of the 18th Annual Conference of the National Advisory Committee on Computing Qualifications, Jul. 10-13, Oxford Brookes University, Tauranga, NZ., pp: 1-8.

Sen, A., K. Ramamurthy and A. Sinha, 2011. A model of data warehousing process maturity. IEEE Trans. Software Eng., 1-1. DOI: 10.1109/TSE.2011.2

Sharma, R.D. and R. Rishi, 2011. Information Technology Infrastructure Library. 